\title{
The Aggression Questionnaire: A Validation Study in Student Samples
}

\author{
Ana García-León'ㄹ, Gustavo A. Reyes ${ }^{1}$, Jaime Vila², \\ Nieves Pérez ${ }^{2}$, Humbelina Robles ${ }^{2}$, and Manuel M. Ramos ${ }^{1}$ \\ 'University of Jaén \\ ${ }^{2}$ University of Granada
}

\begin{abstract}
The goal of this study was to examine the psychometric properties of the Aggression Questionnaire (AQ) in Spain. The AQ is a 29 -item instrument designed to measure the different dimensions of the hostility/anger/aggression construct. It consists of 4 subscales that assess: (a) anger, (b) hostility, (c) verbal aggression, and (d) physical aggression. In Study 1, reliability, construct validity, and convergent validity were evaluated in a group of 384 male and female university students. Testretest reliability was evaluated using a group of 154 male and female university students. The results of the fictor analysis were similar to the scale structure claimed for this instrument. The subscales also showed internal consistency and stability over time. The AQ and its subscales were also compared with the scales and subscales of the Spielberger State-Trait Anger Expression Inventory (STAXI), the Cook-Medley Hostility Scale (Ho), the Buss-Durkec Hostility Inventory (BDHI), and the Jenkins Activity Survey-Form H (JASE-H). The results show that the AQ evaluates some aspects of anger, such as Anger-Trait and Anger-Out, rather than other elements, such as Anger-In or Anger-State. In Study 2, two new male groups were used to evaluate the criterion validity of the AQ: 57 prison inmates and 93 university students, finding that this instrument discriminated between the scores obtained by common offenders and university students.
\end{abstract} Key words: anger, hostility, aggression, questionnaire, factor analysis

\begin{abstract}
El objetivo de este estudio fue examinar las propiedades psicométricas del Cuestionario de Agresión ( $A Q$ ) en España. El $A Q$ es un instrumento de 29 ítems que mide las distintas dimensiones del constructo hostilidad/ira/agresión. Consta de 4 subescalas que evalúan: (a) ira, (b) hostilidad, (c) agreșión verbal y (d) agreșión física. En el Estudio 1 se evaluó la fiabilidad, la validez de constructo y la validez convergente en un grupo de 384 estudiantes universitarios de ambos sexos. También se midió la fiabilidad test-retest, usando un grupo de 154 estudiantes universitarios de ambos sexos. Los resultados del análisis factorial revelaron una estructura similar a la encontrada con muestras de habla inglesa. Las subescalas mostraron una adecuada consistencia interna y fiabilidad test-retest. Igualmente, se calcularon las correlaciones existentes entre el $\mathrm{AQ}$ y otros instrumentos de medida del constructo, tales como el Inventario de Expresión y EstadoRasgo de lra de Spielberger (STAXI), la Escala de Hostilidad de Cook y Medley (Ho), el Imventario de Hostilidad de Buss-Ourkee (BDHI) y la forma $\mathrm{H}$ de la Escala de Actividad de Jenkins (JASEH). Los resultados sugieren que el $A Q$ evalúa algunos aspectos de la ira tales como lra-Rasgo e Ira-Externa más que otros elementos como Ira-Interna o Ira-Estado. En el Estudio 2 se evaluó la validez de criterio del $\mathrm{AQ}$ a partir de dos grupos de varones: 57 reclusos que habian cometido diversos tipos de delitos y 93 estudiantes universitarios. En este caso, se encontró que las puntuaciones obtenidas en el instrumento permitian discriminar entre ambos grupos de sujetos. Palabras clave: ira, hostilidad, agresión, cuestionario, análisis factorial
\end{abstract}

Correspondence concerning this article should be addressed to Ana García León, Dpto. de Psicología. Facultad de Humanidades y Ciencias de la Educación. Universidad de Jaén. Paraje de las Lagunillas, s/n. $23071 \mathrm{Jaén}$ (Spain). E-mail: angarcia@ujaen.es 
The terms anger, hostility, and aggression are often used interchangeably. However, sone researchers consider that hostility, anger, and aggression can represent the cognitive, affective, and behavioral components of the same multidimensional construct (Barcfoot, 1992; Buss \& Perry, 1992). Thus, the construct could consist of three basic dimensions: a) affective, made up of emotions such as anger or loathing; b) cognitive, consisting mainly of negative thoughts about human nature, resentment, and cynical distrust; and c) behavioral, defincd by various forms of aggression, such as physical or verbal aggression. All these factors seem to be related to each other, varying in intensity, frequency, and duration.

A review of the literature shows that there are some problems associated with the measurement of this construct, resulting in some confusion in this area. Some studies did not take into account the multidimensional nature of the construct, finding different instruments to evaluate different components as if they were equivalent measures. In other studies, instruments with questionabic reliability and validity were used (Barefoot \& Lipkus, 1994).

The Aggression Questionnaire (AQ; Buss \& Perry, 1992) does not show either of the problems described above. On the contrary, this instrument evaluates several components of the construct: anger, verbal aggression, physical aggression, and hostility, and it has shown adequate psychometric standards in English-speaking samples (Buss \& Perry, 1992; Harris, 1995, 1997).

The first version (Buss \& Perry, 1992) consisted of 52 items, some borrowed intact from the Buss-Durkee Hostility Inventory (BDHI; Buss \& Durkee, 1957) and others rewritten more clearly. The correlation matrix of the 52 items for a first sample of 406 college students was subjected to principal-axis factoring and oblique rotation. This initial factor analysis was followed by a confirmatory factor analysis on a second and third sample of students. In the first sample. four rotated factors proved to be the maximum interpretable number: Physical Aggression, Verbal Aggression, Anger, and Hostility (a combination of Resentment and Suspicion). This was replicated over the next two samples. Or the list of 52 items, 23 were excluded. The remaining 29 items constitute the original version of the AQ. Buss and Perry (1992) have interpreted aggression as consisting of four subtraits. In this way, Physical and Verbal Aggression would represent the instrumental or motor components, Anger would be the emotional or affective component, and Hostility would represent the cognitive component. Recently, this factorial structure and the subscale distinction of the AQ have also been found in other student samples (Bernstein \& Gesn, 1997; Harris, 1995) but not in an offender population (Williams, Boyd, Cascardi, \& Poythress, 1996).

With respect to its psychometric standards, the results showed adequate test-retest reliability and internal consistency both for the general questionnaire and the subscales (Buss \& Perry, 1992; Harris, 1995, 1997). The internal consistency of the four factors and the total score ranged between .72 and 89. As far as the test-retest reliability is concerned, the analyses yielded a group of indexes, ranging between .72 and 80 (Ando et al., 1999; Buss \& Perry, 1992). The correlations found between the $A Q$ and peer nominations of aggression also showed values around .40, lending support to construct validity (Buss \& Perry, 1992).

Most of the results obtained with the AQ are based on English-speaking samples, but there are not many studies that evaluate the psychometric properties of the $A Q$ in countries where other languages are spoken. Therefore, we believe the instrument should be validated in Spanish samples. This article reports the findings of two validation studies of the AQ in Spain. We used the 29-item original version of the $\mathrm{AQ}$, which was translated to Spanish by the first author of this study.

Our aims were the following: (a) to confirm the factor structure of the AQ in a Spanish sample (construct validity), (b) to determine the internal consistency, split-half reliability, the test-retest reliability of this instrument; (c) to determine whether the Spanish version of the AQ is a good measure of the different components of the construct, such as anger, hostility, physical aggression, and verbal aggression. To this end, we examined the existing relationships between the $A Q$ and other measurement instruments of hostility that evaluate these components (criterion validity using convergent validity); and (d) to verify whether the Spanish version of the $A Q$ is able to discriminate between the scores obtained by common offense inmates and university students (criterion or external validity).

\section{Study 1}

In this first study, reliability, construct validity, and criterion validity (using convergent validity) were evaluated.

\section{Method}

\section{Participants}

This study involved a total of 384 Education and Psychology students at the Universily of Jaén in Spain. There were 90 males and 294 females, with a mean age of 21.6 years $(S D=5.6)$.

To estimate test-retest reliability, we used a different group comprised of 154 Psychology students (34 males and 120 females) from the University of Jaén. Their ages ranged between 17 and 24 , with a mean age of 18.7 years $(S D=1.2)$.

\section{Instruments}

In addition to the $\mathrm{AQ}$, the following instruments were included in the study: 
The Cook-Medley Hostility Scale (Ho; Cook \& Medlcy, 1954). This scale consists of 50 true-or-false jtems taken from the originat MMPI and it is usually used as a measurement of general hostility. The results of factorial analyses suggest the cxistence of various factorial structures. Thus, whereas Cook and Medley obtained a factorial structure based on one factor, which is called Cynicism or Cynical Distrust, other studies (Bermúdez, Sánchez-Elvira, \& Fernández, 1994; Costa, Zonderman, McCrae, \& Williams, 1986) found two factors, called Cynicism and Paranoid Alienation. In terms of reliability, both the English and Spanish versions revealed an internal consistency between .75 and .80 (Bermúdez et al., 1994; García-León, 1999; Smith \& Frohm, 1985). The data of test-retest reliability of the scale show values around .75 (Bishop \& Quah, 1998).

The Buss-Durke Hostility Imentory (BDHI; Buss \& Durkee, 1957). This instrument seems to be useful for measuring both the experience and the expression of hostility. The English version of the inventory is made up of 75 items in a true-false format, consisting of eight theoretical subscales based on clinical criteria: assault, indirect hostility, irritability, negativism, resentment, suspicion, verbal hostility, and guilt. The eight scales were established a priori, and no factor analysis of items was carried out. In the original study by Buss and Durkee, two factors were found. The first factor contained items assessing assault, indirect aggression, initability, and verbal aggression and was called Overt Hostility or Expression of Hostility. The second factor was defined by items assessing resentment and suspicion and was called Covert Hostility or Experience of Hostility. These factors are considered two independent dimensions. General internal consistency of the BDHI was between .57 and .78 for the original version (Bishop \& Quah, 1998; Taugney, Wagner, Fletcher, \& Gramzow, 1992) and 86 for the Spanish version (García-León, 1999). The resulting items of the overt hostility subscalc had an alpha reliability of .76 , whereas the items of covert hostility subscale had an alpha of .72 (Bendig, 1962). Temporal consistency or test-retest reliability of the BDHI was .82 (Biaggio, Supplee, \& Curtis, 1981).

The Jenkins Activity Scale-Form $H$ (JASE-H; Krantz, Glass, \& Snyder. 1974). This instrument is comprised of 32 items that evaluate the Type A pattern, both globally and in its different components. Bermúdez, Pérez García, and Sánchez-Elvira (1991) validated the Spanish version by means of factor analysis, starting with the Jenkins Activity Scale-Form T (Krantz, Glass, \& Snyder, 1974) and the Irritability Scale by Caprara et al. (1985). The scale consists of four subscales entilled: Hard Driving ( 8 items), Job Involvement (6 ilems), Impatience ( 5 items), and Hostility (7 items). It showed adequate reliability both for the globa] Type $A$ and for the subscales. With regard to reliability of the general instrument and its subscales, both the English and Spanish versions showed alpha reliability values betwcen .75 and .88 . On the other hand, temporal consistency of this instrument ranged between .84 and .92 (Bermúdez et al., 1991; Krantz et al., 1974).

The State-Trait Anger Expression Inventory (STAXI; Spielberger, 1988). This instrument consists of 47 items to assess both anger experience and anger expression. Anger experience is measured on two dimensions: Anger-State (11 items) and Anger-Trait ( 11 items). Anger expression is measured on three dimensions: Anger-Out (10 items), AngerIn ( 7 items), and Anger-Control ( 8 items) (Forgays, Forgays, \& Spielberger, 1997; Fuqua et al., 1991; Kjell, 1994; MiguelTobal, Casado, Cano-Vindel, \& Spiciberger, 1997; Spielberger, 1988). Fuqua et al. (1991) obtained only moderate values of internal consistency for the general instrument, suggesting the need to use the subscales independently. When these subscales were studjed in a Spanish population, values between 63 and .95 for the alpha Cronbach coefficients were found (Biaggio, 1994; Fcrnández-Abascal \& Martin, 1995; Miguel-Tobal et al., 1997).

All of these instruments were selected for two reasons. First, they have frequently been used to evaluate the construct, and second, the psychometric properties of these measures ate available for Spanish population.

\section{Procedure}

The group of 384 students filled in the $\mathrm{Ho}$, the $\mathrm{AQ}$, the BDHI, the JASE-H and the STAXI in group sessions in their usual classes. Administration of the instruments was counterbalanced. Participants took approximately 45 minutes to fill in all the tests.

To calculate test-retest reliability, the $\mathrm{AQ}$ was administered to a group of 154 students twice, with a 5week interval. Both administrations of the $A Q$ were carried out in group sessions in the classes.

\section{Results}

\section{Factor Analyses (Construct Validity)}

The correlation matrix of the 29 items was subjected to principal component analysis and oblimin rotation. We used the following criterion to select the items for a factor: an item had to load at least .35 on its own factor but less than .35 on any other factor. Four rotated factors, which could explain $42.1 \%$ of total variance, proved to be the maximum number interpretable. These factors were called: (a) Anger with Resentment (items 3, 4, 7, 8, 11, 12, 16, 22, and 25); (b) Verbal Aggression (items 2, 6, 10, 13, 14, 15, 18, and 19); (c) Physical Aggression (items 1, 5, 9, 17, 27, and 29); and (d) Suspicion (items 20, 23, 26, and 28). The results are presented in Table 1 . The data revealed that the original four-factor structure was replicated in the 
Table 1

Factor Loadings for Oblimin Four-Factor Solufion

ltems

Factor loadings

Factor 1: Verbal Aggression

18. My friends say that l'm somewhat argumentative

6. I often find myself disagreeing with people.

13. I get into fights a little more than the average person does.

.60

14. I can't help getting into arguments when people disagree with me.

.58

19. Some of my friends think l'm a hothead.

10. When poople annoy me, I may tell them what I think of them.

2. I tell my friends openly when I disagree with them.

15. I am an even-tempered person.

Factor II: Anger with Resentment

16. I wonder why sometimes I fecl so bitter ahout things.

8. At times, I feel I have gotten a raw deal out of life,

4. I am sometimes eaten up with jealousy.

11. I sometimes feel like a powder keg ready to explode.

22. Sometimes, I fly off the handle for no good teason.

12. Other people always seem to get the breaks.

25. I have trouble controlling my temper.

7. When frustrated, I let my irritation show.

3. I flare up quickly but get over jt quickly.

Factor III: Physical Aggression

5. Given enough provocation, I may hil another person. $\quad .80$

9. If somebody hits me, I hit back. $\quad .75$

17. If I have to resort to violence to protect my rights. I will. $\quad .71$

1. Once in a while, I can't control the urge to strike another person. $\quad .62$

27. I have threatened people I know. 48

29. I have become so mad that I have broken things. $\quad .42$

Factor IV: Suspicion

28. When people are especially nice. I wonder what they want. $\quad .75$

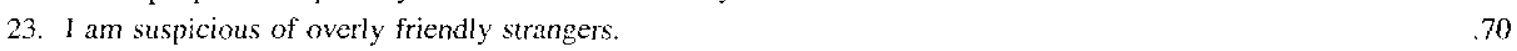

20. I know that "friends" talk about me behind my back.

26. I sometimes feel that people are laughing at me behind my back.

Note. $\mathrm{sl}=384 ; a=.82$

Spanish sample, showing the existence of a relatively constant structure among different versions of the AQ. When equating the number of males and females in the sample $(n=180)$ and performing a principal component factor analysis with oblimin rotation, nine factors were obtained. Four of these factors were similas to the original four factors of Buss and Perry (1992), but the remaining live had no clear psychological interpretation. This solution was therefore discarded.

The correlations among factors (or subscales) are presented in Table 2. The results are similar to those obtained by Buss and Perry (1992). although the value of our scores was lower than the scores of the original version. As might be expected, the subscales of Verbal and Physical
Aggression were correlated. Likewise, the subscale of Anger with Resentment correlated with the other three subscales.

With regard to sex differences, the results are presented in Table 3. Men had significantly higher scores on Physical Aggression, $F(1,370)=16.61, p<.001$, and Verbal Aggression, $F(1,363)=7.94, p<.01$, whereas women had significantly higher scores on Anger with Resentment, $F(1$, $359)=17.64, p<.001$. In order to guarantee that the differences observed were not due to the different number of participants in the groups of men and women, the analysis was repeated using the same number of males and females ( $n=90$ males and 90 females), obtaining practically the same results as in the original groups. 
Table 2

Correlations anong the Aggression Subscales

\begin{tabular}{lccc}
\hline Subscale & Verbal Aggression & Physical Aggression & $.33^{* *}$ \\
\hline $\begin{array}{l}\text { Anger with Resentment } \\
\text { Verbal Aggression }\end{array}$ & $.31^{* *}$ & $.48^{* *}$ \\
Physical Aggression & & .15 & $.21^{* *}$ \\
\hline
\end{tabular}

Note. $n=384$.

$* * p<.01$

\section{Reliability Analyses}

Internal consistency of the four factors and the total score was ovaluated by the alpha coefficient, obtaining the following values: Verbal Aggression, .57; Physical Aggression, .63; Anger with Resentment, .77; Suspicion, .67 ; and total score, .82. In general, the alpha for the total score indicated considerable internal consistency. The alphas for the individual subscales showed lower but adequate scores for subscales with fewer than eight itcms.

Split-half reliability was based on the analyses of the correlation coefficient between even and odd items, corrected by the Spearman-Brown coefficient, obtaining the following values: Verbal Aggression, .54; Physical Aggression, .76: Anger with Resentment, .71; Suspicion. .48 ; and total score, .85 .

With regard to test-retest reliability, in the group of 154 subjects who filled in the AQ twice (with a 5-week interval), the results were as follows: Verbal Aggression, .72; Physical Aggression, .81; Anger with Resentment, .88; Suspicion, .57 ; and total score, .81 . These coefficients suggest marked stability over time.

\section{Criterion Validity using the Convergent Validity}

We examined tha relationship between the $A Q$ and other instruments used to assess the construct: Ho, BDHI, STAXI, and JASE-H. In general, the analyses showed adequate alpha reliability values (between .75 and .90 ) for the Spanish version of these instruments (Bermúdez et al., 1991; Bermúdez et al.. 1994; García-León, 1999; Miguel-Tobal et al., 1997), which are even higher than the indexes reported previously in the literature. The correlations of the aggression subscales with various hostility and anger scales are shown in Table 4.

Firstly, the Ho showed the highest correlations with the total AQ score and with the subscales of Anger with Resentment and Suspicion. Secondly, both the total AQ score and all its subscales correlated strongly with the BDHI. Some items of the AQ were borrowed intact from the BDHI. This might have partially influenced the high correlations found between both instruments. However, high correlations were also found between the $A Q$ and other instruments used in the study, whose items are different from the items of the AQ (see correlation matrix in Table 4). For this reason, we think that the high correlations are not an artifact of the study. Thirdly, the JASE-H and its subscales of Impatience and Hostility also showed the highest correlations with the total AQ score and with the Anger with Resentment subscale. Lastly, the instrumental components of Physical and Verbal Aggression also correlated modestly with the Anger-Out subscale of the STAXI but not with its Anger-In subscale. Both the total $A Q$ score and the Anger with Resentment subscale correlated strongly with the Anger-Trait and the Anger-Out subscales of the STAXI.

Table 3

Sex Differences in the Four Aggression Subscales

\begin{tabular}{|c|c|c|c|c|c|c|}
\hline \multirow{2}{*}{ Subscales } & \multicolumn{2}{|c|}{ Men $n=90$} & \multicolumn{2}{|c|}{ Women $n=294$} & \multirow[b]{2}{*}{$F$} & \multirow[b]{2}{*}{$d f$} \\
\hline & $M$ & $S D$ & $M$ & $S D$ & & \\
\hline Anger with Resentment & 24.9 & 7.3 & 28.7 & 7.0 & $17.64 * * *$ & 1,359 \\
\hline Verbal Aggression & 22.8 & 5.4 & 21.1 & 4.4 & $7.94 * *$ & 1,363 \\
\hline Physical Aggression & 13.2 & 5.5 & 11.0 & 4.0 & $16.61^{* * *}$ & 1. 370 \\
\hline Suspicion & 8.8 & 3.4 & 9.6 & 3.7 & 3.28 & 1.378 \\
\hline Total score & 74.3 & 15.5 & 76.1 & 14.4 & 0.83 & 1,381 \\
\hline
\end{tabular}

$* * p<.01, * * * p<.001$ 


\section{Study 2}

In this study, the criterion validity of the AQ wats cvaluated by testing for hypothesized differences between contrast groups of common-offense prison inmates and students.

Method

Participants

Two new groups were used in this study. The first group was made up of 57 inmales of the prison of Jaen, who were mainly incarcerated for armed robbery, robbery, aggravated assault, or drug-related offenses. They were all males, with a ntean age of 20.7 years $(S D=2.9$ ). The second group wals made up of 93 university students. They were also all males. with a mean age of 19.5 years $(S D=1.5$ ).

\section{Procedure}

Both groups were administered the $\mathrm{AQ}$ in group sessions. University students frlled in the questionnaire in their usuat classroons. and prison inmates in a leisure room of the prison. The prison inmates were volunteers, and they were informed that the results of the $A Q$ would be a pirt of their psychological assessment.

\section{Results}

\section{Criteriom or External Validity}

We calried out one-way analyses of variance. The means and standard deviations are displayed in Table 5. In general, we expected prison inmates to show higher scores than university students both in the AQ total and in its subscales.

The statistical analyses revealed one significant difference between groups. Specifically, inmates scorcd significanty higher than did students in Physical Aggression. F(1, 145) $=24.01, p<.01$. In relation to the total score and Suspicion, although the differences were not statistically significan, higher scores were observed in prison intnates than in university students.

Table 4

Correlations between the Aggression Questionnaire and other Hostility and Anger Instruments

\begin{tabular}{|c|c|c|c|c|c|}
\hline \multirow{2}{*}{ Hostility \& Anger Scales } & \multicolumn{5}{|c|}{ Aggression Questionnaire } \\
\hline & Anger with Resentment & Verbal Aggression & Physical Aggression & Suspicion & Total score \\
\hline Tutal Ho & $.53 * *$ & $.19^{* *}$ & $.34 * *$ & $.56 \div \%$ & $.59 \%$ \\
\hline Total BDIII & $.68^{* * *}$ & $.37 \times * *=$ & $.53 *$ & $.55 *:$ & $.79 \% *$ \\
\hline Total JASE-H & $.42^{* * *}$ & .31 k $k !$ & $.35^{2 *}$ & $.25^{* ;:}$ & $.51^{* * *}$ \\
\hline JASE-HD & .03 & $.25^{* * k}$ & .17 & .03 & .10 \\
\hline JASE-HIL & $.24 * *$ & .13 & .10 & .37 & $.26 * *$ \\
\hline JASE-HI & $.50^{* * *}$ & $.21 * *$ & $.32^{* \%}$ & $.32^{* *}$ & $.53 * *$ \\
\hline JASE-HH & $.67 * * 4$ & $.29+4$ & $.47 \% \%$ & $.35 * *$ & $.68 * *$ \\
\hline Total STAXI-T & $.49^{* * *}$ & $.25^{*}:$ & $.32 * *$ & $.34^{4 * k}$ & $.53 * *$ \\
\hline STAXI-RT & $.28^{* * *}$ & $.19 \div *$ & $.22 \%$ & $.25 *$ & $.35 * *$ \\
\hline STAXI-RR & $.52^{3 * *}$ & $22^{*: \pi}$ & $23^{* * *}$ & $.29^{* * 1 *}$ & $.5 ; * *$ \\
\hline Total STAXI-EX & $.32 * *$ & $.25 * *$ & $.22^{* k}$ & $26^{* * * 1}$ & $.39 * * *$ \\
\hline STAXI-EXI & $.32 \%:$ & .09 & .17 & $.30^{* * 1}$ & $.33^{* *}$ \\
\hline STAXI-EXE & $.50 * *$ & $.43 * *$ & $.38 * k$ & $.30^{k *}$ & $.60^{1 * *}$ \\
\hline STAXI-EXC & $-.34: *$ & -.12 & $-.23 * *$ & $\cdots .17$ & $-.33 * *$ \\
\hline Total STAXI-S & $.24^{* * *}$ & .09 & .17 & $.18^{28}$ & $.25 \%$ \\
\hline
\end{tabular}

Nore. $n=384$. Ho $=$ Cook-Medley Hostilicy Scale. BDHI = Buss-Durkee Hostibity Inventory.

JASE-H = Jenkins Activity Scale, form H: JASE-HI = Subscale of Hard-Driving: JASE-HJI = Subscale of Johl Involvement: JASE-HI $=$ Subscale of Impatience: JASE-HH = Subscale of Hostility.

STAXI-T = Subscale of Anger-Trait from the State-Trait Anger Expression Inventory: STAXI-R $\mathrm{f}=$ Subscale of Tompcrament: STAXI$R R=$ Subscale of Reuction: STAXI-EX = Subscale of Anger Expressioni; STAXI-EXI = Subscate of Anger-[n; STAXI-EXE = Subsedite of Anger-Our; STAXI-EXC = Subscale of Anger-Control; STAXI-S = Subscale of Anger-State.

$: k<<01$ 
Táable 5

Group Differences in the Fow Subscales of the Aggreswion Questionnaire

\begin{tabular}{|c|c|c|c|c|c|c|}
\hline \multirow{2}{*}{ Subscales } & \multicolumn{2}{|c|}{ Iniversity Students $n=93$} & \multicolumn{2}{|c|}{ Prison Inmates $n=57$} & \multirow[b]{2}{*}{$F$} & \multirow[b]{2}{*}{$d f$} \\
\hline & $M$ & $S D$ & $M$ & $S D$ & & \\
\hline Anger with Resentment & 25.9 & 6.6 & 26.2 & 7.2 & .06 & 1,137 \\
\hline Verbal Aggression & 21.5 & 5.0 & 22 & 5.1 & .38 & 1.141 \\
\hline Physical Aggression & 12.9 & 4.9 & 17.3 & 5.6 & $24.01 * *$ & 1,145 \\
\hline Suspicion & 10 & 3.1 & II & 4. 1 & 2.96 & 1,144 \\
\hline Total score & 75.7 & $\lfloor 4.9$ & 80.4 & 15.3 & 2.83 & 1,132 \\
\hline
\end{tabular}

$* *_{p}<.01$

\section{Discussion}

The principal aim of this study was the analysis of the AQ. The psychometric properties of this questionnaire in English-speaking samples suggested that it would be adequate for evaluating hostility, anger, and aggression in a Spanish sample.

The first goal of this work was to evaluate the factor structure of the AQ to detcrmine the extent to which the structural properties of the inventory corresponded to the theoretical constructs upon which the $\mathrm{AQ}$ and its subscales were based. We also wanted to verify whether the items of each of the $A Q$ subscales had salicnt loadings on the appropriate factors.

The factorial analyses of the $\mathrm{AQ}$ carricd out by Buss and Perry (1992) revealed four specific factors. which were called Physical Aggression, Verbal Aggression, Hostility, and Anger. From a theoretical point of view, Buss and Perry considered that this group of factors represented the full range of components of the construct. Thus, they established that the Physical Aggression and Verbal Aggression factors included the items related to the instrumental or behavioral components, the Hostility factor represented the cognitive component, and the Anger factor was based on the affective or emotional elements of the construct.

The factor structure found in the sample of Spanish students coincides closely with the conceptual and empirical structures suggested in the study by Buss and Perry (1992). However, there are some discrepancies with regard to the items included in the various factors. The behavioral components did not vary very much between Spanish and English-speaking samples, although both a decrease in the number of elements in Physical Aggression and an increase in the items representing Verbal Aggression in the Spanish sample could be observed when compared with the Englishspeaking sample. In contrast, therc are some differences between English-speaking and Spanish samples when the cognitive and emotional components are analyzed. When examining the results obtained on these factors in the Spanish sample, we observe the appearance of a subscale of Anger with Resentment (simika to the subscale of Anger) and a subscale made up only of the elements of Suspicion (similar to the subscale of Hostility). This suggests that the aspects associated with resentment are considered by the Spanish population to have high emotional content, whereas aspects related to suspicion or mistrust of others remain in the cognitive component.

The correlation between Physical Aggression and Verbal Aggression was expected because it is considered that both factors are different, but complementary, aspects of instrumental behavior. It was not surprising that these elements showed a lower correlation with the cognitive factor of Suspicion. We also found modest cotrelations between the subscale of Anger with Resentment and the other three components (Verbal Aggression, Physical Aggression, and Suspicion), although the strength of the relationship with the Physical and Verbal Aggression subscales was lower than that found in relation to the Hostility component in the original study. In this case, the items related to a cognitive factor such as resentment have been included in the subscale of Anger with Resentment, which partially explains why this subscale presents the highest correlation with the subscale of Suspicion. In other words, even though anger may be a prelude to aggression, as Buss and Perry (1992) suggested, it seems to play a more important role in the presence and duration of thoughts associated with suspicion about other's people motives.

The sex differences found are also interesting and lend support to the idea that the individual scales provide more detailed information than the total score. Men were physically and verbally more aggressive than women, as in the study of Buss and Perry (1992), but contrary to what we expected, women showed higher scores in the subscale of Anger with Resentment than men. These data may suggest that some Spanish women become angrier than do some Spanish men, but the women inhibit expressing this anger with hostile aggression. In accordance with Brody (1985), we think that display rules and social pressures placed upon males and females are particularly divergent in the arca of anger. Thus, whereas males usually inhibit the expression of most cmotions, females selectively inhibit the expression of socially unacceptable cmotions, such as anger. 
With regard to reliability, our results confirm those found in the English-speaking sample, athough our scores reveal slightly lower values for some subscales than the values obtained in the first sample. We think that this may be partially explained by the reduced number of items that make up some subscales and also to the smaller number of participants in our study. Howcver, it seems that this instrument is suitable to evaluate the hostility construct, showing adequate reliability in a Spanish sample,

Both the total score and the individual subscales of the questionnaire show different correlations with other measurements of hostility, anger, and aggression. The BDHI presented the strongest relations with the $\mathrm{AQ}$ and all its subscales. The literature about the BDHI considers that it is made up of a group of items that represent different aspects of hostility (Biaggio \& Maiuro, 1983); in this sense, we think that these correlations confirm the existence of four different components of the construct in the AQ. In relation to the Ho, higher coefficients were found between this scale and both the total score of the $A Q$ and its subscales of Anger with Resentment and Suspicion. Taking into account the conclusions of some studies that point out the importance of the Ho to measure fundamentally the cognitive components of the construct (Hardy \& Smith, 1988), these results seem to support the ability of the AQ to evaluate this element. The instrumental components of Physical and Verbal Aggression also correlated modestly with the subscales of Anger-Trait and Anger-Out of the STAXI, but not with its subscales of Anger-State or Anger-In, suggesting that the $\mathrm{AQ}$ could evaluate some aspects of anger, but not others. As Buss and Peny (1992) suggest, we think that the results demonstrate the importance of dividing aggression into its components or subtraits.

The group dilference found in the component of Physical Aggression in Study 2 is also of some relevance. Male prison inmates are usually more aggressive than male students. Although in the remaining scores, the differences were not statistically significant, inmates scored higher than did students in the total score and in Suspicion. As suggested above, the AQ seems to be an adequate questionnaire in terms of discriminating between different groups. The high scores found among inmates only in the subscale of Physical Aggression again show the importance of measuring separately each one of the four components of hostilicy.

\section{References}

Ando, A., Soga, S., Yamasaki, K.. Shimai, S., Shimada, H.. Utsuki. N., Oashi, O.. \& Sakai. A. (1999). Development of the Japanesc version of the Buss-Perry Aggression Questionnate (B,AQ). Shimigakn Kenkya, 70, 384-392.

Barefoot, J.C. (1992). Developments in the measurement of hostility. In H.S. Friedman (Ed), Hostility coping and heshlth (pp. 1.3-3l). Washington, DC.: American Psychological Association.

Barcfoot. J.C. \& lipkus, I.M. (1994). The assessment of anger and hostility. In A.W. Siegmals \& T.W. Smith (Eds.), Anger, hostility and the heat (pp. 43-66). Hillsdalc. NJ: Erlbaum.

Bendig. A.W. (1962). Factor analytic scales of covert and overt

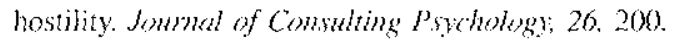

Bermúdez. J., Pérez García. A.M.. \& Sánchez-Elvira. A. (1991). Imortario de medida del patrón de condura tipa-A: JASE-H. Unpublished manuscript, Universidad Nacional de Educación a Distancia, Maturid.

Bermúdez, I. Sáuchez-Elvira, A., \& Fernándę, E. (1994, September). Contenido del Imentario de Howilidad de Cook $y$ Medley (ICM): implicaciones pronocoronarias. Paper presented at the IV Congreso de Evaluación Psicológica. Santiago de Compostela, España,

Bernstein. I.H.. \& Gesn. P. R. (1997). On the dimensionality of the Buss/Perty Aggression Questionnaire. Behavior Research and Therapy, 35, 563-568.

Biaggio, M.K. (1994). Studies of the experience, expression and control of anger in Brasil. Paper presented at the $23^{\text {rd }}$ International Congress of Applied Psychology, Madrid. Spain.

Biaggio. M.K. \& Maiuro, R.D. (1983). Recent advances in anger assessment. In J,N. Butcher \& C.D. Spielberger (Eds.). Adrances in personality assessment (pp. 71-111). Hilssdale. $\mathrm{NJ}$ : Erlbaum.

Biaggio, M.K. Supplee. K., \& Curtis, N. (1981). Reliability and validity of four anger scales. Joumal of Perwondity Asseswment. 45, 639-648.

Bishop. G.D. \& Quah. S. (1998). Reliability and validity of measures of anger/hostility in Singapore: Cook \& Medlcy Ho Scale, STAXI, and Buss-Durkee Hostility Imventory. Personality and Individual Differences, $24,867.878$.

Brody. L.R. (1985). Gender differences in emotional development: $A$ roview of theories and research. Sournal of Personality 53 , 102-149.

Buss, A.H., \& Durkce, A. (1957). An inventory for assessing different kinds of hostility, Joumal of Constlting P.ychology. 21. 343-349. (Spanish version: García-León. A., Pérez-Marfil, M.N., Valencia-Naranjo. N.J.. Muñoz-López. J., \& Reyes del I'aso, G.A. The Buss-Durkee Hostility Imentory: Its adaptation ro the Spanish population. Paper presented at the 23r lnternational Congress of Applied Psychology, Madrid. Spain. 1994h, May.'

Buss, A.H. \& Perry, M. (1992). The Aggression Questionnaire. Jomal of Personality and Social Psycholog, 63, 452-459.

Capprara, G.V.. Cinanni, V., D'Imperio. G.. Passerini, S., Renzi. P. \& Travaglia, G. (1985). [ndicators of impulsive aggression: Present status research of Irritability and Emotional Susceptibility Scales. Personality and Indinidual Differences, 6. 665-674.

Cook, W. \& Madley. D. (1954). Proposed hostility for plarisajcvitue skills of the MMPl. Jounal of Applied Psychotogy, 38, 414-418. (Spanish version: García-León, A., Pérez. M.N.. Robles. H. \& Vilonciá, N. J. Estrolio psicométrica del Cook- 
Medley Hostiliy Scale (Ho). Paper presented at the IV Congreso de Evaluación Psicológica, Santiago de Compostela, Spain. 1994a, September.)

Costa, P.T, Zondernan, A.B., McCrae. R.R., \& Williams, R.B. (1986). Cynicism and paranoid alienation in the Cook and Medley Hostility Scale. Psychosomatic Medicine, 48, 283-285.

Fernández-Abascal, E.G., \& Martín. M.D. (1995). El síndrome AHA y su relación con los trastomos cardiovasculares. Ansiedad y Estrés, 0. 25-36.

Forgays, D.G. Forgays, D.K.. \& Spielberger, C.D. (1997). Factor structure of the State-Trait Anger Expression Inventory. Joumal of Personality Assessment, 69, 497-507.

Fuqua, D.R. Lconard, E., Masters. M.A., Smith, R.J., Campbell, J.L., \& Fischer, PC. (1991). A structural analysis of the StateTrait Anger Expression Imventory. Educational and Psychological Measurement, 51, 439-446.

García-León, A. (1999). Efectos de la hostilidadira sobre la reactividad cardiovascular en paradigmas tóntcos y fásicos (la Respuesta Cardiaca de Defentsa). Jaćn. Spain: Servicio de Publicaciones de la Universidad de Jaén.

Hardy, J., \& Smith, T. (1988). Cynical hostility and vulnerability to disease: Social support, life stress, and physiological response to conflict. Health Psychology, 7. 447-459.

Harris, J.A. (1995). Confirmatory factor analysis of the Aggression Questionnaire. Behavior Research and Therapy, 8, $991-993$.

Harris, J.A. (1997). A further evaluation of the Aggression Questionnare: Issues of validity and reliability. Behovior, Research and Therapy, 35, 1047-1053.

Kjell, H. (1994, May). Factor structure of the Nonvegian adaptation of Spielberger's State-Trait Anger Expression Scale (STAXI). Paper presented at the $23^{\text {rd }}$ International Congress of Applied Psychology, Madrid, Spain.
Krantz, D.S., Glass, D.C. \& Snyder, M.L. (1974). Helplessness. stress level, and the coronary-prone behavior pattern. Joumal of Experimental Social Psychology, 10, 284-300. (Spanish translation: Bermúdez, J., Pérez Garcia, A.M. \& SánchezElvira, A. (1991). Inventario de medida del patón de conducta tipo-A.: JASE-H. Unpublished manuscript, Universidad Nacional de Educación a Distancia. Madrid.)

Miguel-Tobal, J.J., Casado, M.I, Cano-Vindel, A.. \& Spielberger, C. D. (1997). El estudio de la ira en los trastornos cardiovasculares mediante el empleo del inventario de Expresión de Ira-Estado-Rasgo (STAXI). Ansiedad y Estrés, 3, 5-20.

Smith. T.W. \& Frohm, K.D. (1985). What's so unhealthy about hostility? Construct validity and psychological correlates of the Cook and Medley Ho scale. Healh Psychology, 4, 503520 .

Spielberger, C.D. (1988). State-Trait Anger Expression Mwentory, Odessa. FL: Psychological Assessment Resources. (Spanish Version: Fernández-Abascal, E.G., \& Martín. M.D. (1995). E] síndiome AHA y su relación con los trastornos cardiovasculares. Ansiedad y Estrés, 0, 25-36.)

Taugney, J.P., Wagner. P., Fletcher, C., \& Gramzow, R. (1992). Shamed into anger? The relation of shame and guilt to anger and self-reported aggression. Joumul of Personality and Social Prychology, 62, 669-675.

Williams, T.Y., Boyd, J.C., Cascardi, M.A., \& Poythress, N. (1996). Factor structure and convergent validity of the Aggression Questionnaire in an offender population. Psychological Assessment, 8, 398-403.

Received October 30,2000 Revision received March 31, 2001 Accepted April 25, 2001 